\title{
CUMLAUDE
}

\author{
CUM LAUDE \\ Revista del Doctorado en Derecho \\ Facultad de Derecho y Ciencias Sociales y Políticas UNNE \\ $\mathrm{N}^{\circ} 4$ - Abril 2017 \\ Corrientes - Argentina \\ ISSN: 2422-6408 \\ info@revistacumlaude.com \\ FECHA DE RECEPCIÓN: 12/11/2014 \\ FECHA DE ACEPTACIÓN: 01/11/2016
}

\section{CUMPLIMIENTO DE LAS RESOLUCIONES JUDICIALES EN LOS Procesos Judiciales de Derecho de FAmilia}

\author{
Elisa Manuela Schulz
}

UNIVERSIDAD NACIONAL DEL NORDESTE

\section{RESUMEN}

Las astreintes son un medio efectivo para conminar al cumplimiento de una orden judicial a la parte que es reticente a ello, especialmente en el derecho de familia, donde, la mayoría de las veces, las acciones cuya ejecución se pretende por vía judicial no son sustituibles por dinero. Son un medio de presión psicológica utilizado por la justicia para constreñir al cese de la reticencia al cumplimiento de un mandato suyo. De oficio o a pedido de parte, el juez fija una suma de dinero por día, semana, mes, etc. que transcurra sin que la orden dispuesta sea cumplida. Funciona dentro de la lógica de que si el obligado no cumple por convicción o apego a las decisiones judiciales, cumplirá para no verse afectado en su economía. En ese sentido es un medio muy efectivo. 


\title{
Cumplimiento de las Resoluciones Judiciales en los Procesos Judiciales DE DERECHO DE FAMILIA
}

\section{Palabras Claves}

Astreintes - Familia - Ejecución.

\begin{abstract}
The astreintes (periodic penalty payments) are an effective mean to demand the compliance of a judicial order to the part who is reticent to it, specially in family law, where, most of times, money does not substitute the actions which their executions are alleged in a judicial way. They are a mean of psychological pressure used by justice to oblige the end of the reluctance to the compliance of a judicial order. Ex-officio or at the petitioner's request, the judge set an amount of money for day, week, month, etc. to pay if the time go by without the compliance of that order. It work inside the logic that if the obliged doesn't comply for conviction or faith in the law, he will comply to not being affected in his economy. In that sense it's a very effective way.
\end{abstract}

\section{KEYWORDS}

Astreintes - Family - Execution

Sabido es que los procesos judiciales versados en cuestiones de familia se basan en reglas muy diferentes a las establecidas para otros tipos de juicios.

Si bien ni el código de rito correntino ni el nacional prevén una regulación específica para los mismos -aun cuando el Código Civil y Comercial de la Nación incorporó normas de carácter procesal- en la práctica se evidencia que, más allá de los lineamientos generales dispuestos por la ley para los distintos procesos (ordinario, sumario y sumarísimo), cada juicio de derecho de familia tiene sus propias 
características, distintas a cualquier otro, siempre determinadas por los avatares que presenta la realidad de las partes, la que, muchas veces, cambia continuamente, debiendo entonces el proceso adaptarse a esa situación.

En este tipo de juicios, sobre todo en aquellos en que hay un conflicto de intereses (en contraposición con los procesos meramente homologatorios del acuerdo arribado por las partes), no solo se encuentran sobre el tapete los problemas existentes entre los justiciables y el derecho que cada uno alega como propio, sino que también los sentimientos y las emociones juegan un papel preponderante en la cuestión.

Y son esos sentimientos, emociones y -por qué no- pasiones, tan personales, los que muchas veces llevan a los litigantes a ubicarse en un lugar completamente alejado de la lógica y la razón y, en consecuencia, a comportarse, incluso, en contra de sus propios intereses y los de las personas que eventualmente se encuentren a su cargo o cuidado.

Estas situaciones son una constante en este tipo de conflictos y, no solo quedan expuestas en las presentaciones judiciales realizadas por los letrados de las partes o en las eventuales audiencias realizadas en las causas, sino que afloran constantemente, tanto en la ventanilla de los juzgados como en la oficina de los abogados. Y esto es así porque el mayor interés del justiciable es la solución de su problema, el que, la mayoría de las veces, atañe una parte sustancial de su vida y su persona, no un interés meramente económico o de otra índole material.

El reclamante necesita una respuesta de manera urgente, la cual, indefectiblemente, se encuentra en manos de los tribunales encargados de impartir justicia. 


\section{Cumplimiento de las Resoluciones Judiciales en los Procesos Judiciales DE DERECHO DE FAMILIA}

La mayoría de las veces, la resolución de los diferentes conflictos suscitados durante el proceso no solo queda plasmada en la sentencia definitiva, sino también en las resoluciones dictadas durante su transcurso, como consecuencias de las variadas cuestiones presentadas (ya sea que hayan tramitado vía incidental o no), y cuyo cumplimiento es obligatorio para las partes.

Más allá de las subjetividades de cada caso, no puede negarse que una "victoria" en una incidencia o en un planteamiento de cualquier tipo dentro de un proceso judicial genera en quien resultó vencedor, una expectativa de que el derecho que le fue reconocido se traduzca en la realidad mediante la efectivización de la orden impartida.

Sin embargo -y esto no es exclusivo del derecho de familia- los obligados al cumplimiento de determinada acción no siempre están dispuestos a hacerlo. Y menos aún si a la reticencia normal de las personas a hacer algo que no desea o que cree injusto, le añadimos los componentes emocionales que presentan los juicios de familia.

Entonces, juzgado, abogados de parte y justiciables se encuentran ante el problema de cómo lograr de parte del vencido el cumplimiento de la manda judicial.

\section{EJECUCIÓN FORZADA DE LA MANDA JUDICIAL}

Evidenciada la negativa del obligado al cumplimiento de la orden impartida por el Juzgado, no resta más que la ejecución forzada de la misma mediante los métodos que la ley brinda.

La ejecución forzada puede ser directa (cumplimiento en especie) o indirecta (mediante indemnización de daños y perjuicios).

El art. 730 del Código Civil y Comercial establece que 
La obligación da derecho al acreedor a: a) emplear los medios legales para que el deudor le procure aquello a que se ha obligado; b) hacérselo procurar por otro a costa del deudor; c) obtener del deudor las indemnizaciones correspondientes.

En este caso nos interesa la ejecución directa del derecho reconocido judicialmente, la que variará de acuerdo al tipo de obligación que pese sobre el condenado a su cumplimiento.

Si la obligación es de dar, ya sea determinada cosa o suma de dinero, no existirían mayores problemas en su ejecución compulsiva, ya que si esa cosa o suma de dinero se encuentra efectivamente en el patrimonio del obligado, podría ser objeto de embargo, secuestro o cualquier otra medida de ejecución prevista en los códigos de rito y que aseguren la satisfacción del derecho de la parte interesada.

Por ejemplo: los bienes de la sociedad conyugal que se encuentran en poder de uno de los ex cónyuges que se niega a entregarlos a quien le fueran adjudicados, o la ejecución forzada de los alimentos fijados judicialmente.

Sin embargo, la solución no es tan simple cuando la prestación adeudada no se traduce en un dar, sino que implica un hacer o no hacer.

El Código Civil y Comercial define en sus artículos 773 y 778 respectivamente, a las obligaciones de hacer como aquellas cuyo objeto consiste en la prestación de un servicio o en la realización de un hecho, en el tiempo, lugar y modo acordados por las partes; ya las de no hacer como aquellas que tienen por objeto una abstención del deudor o tolerar una actividad ajena.

Ante el incumplimiento imputable al obligado, el referido cuerpo legal (art. 730) dispone que el acreedor tiene derecho a exigir el cumplimiento específico, hacerlo cumplir por terceros a costa del deudor o reclamar los daños y perjuicios. 


\section{Cumplimiento de las Resoluciones Judiciales en los Procesos Judiciales DE DERECHO DE FAMILIA}

El límite al cumplimiento específico de la obligación está dado por el impedimento de ejercer violencia física sobre el obligado, de la forma en que lo establecía el art. 629 del Código Civil, por aplicación del principio "Nemo poteste precisae cogi ad factum", tal como refiere Compagnucci de Caso (2014).

En caso de que el obligado se negare al cumplimiento en especie, el acreedor puede solicitar el su cumplimiento por un tercero o solicitar una indemnización por los daños y perjuicios que se le ocasionaron.

Sin embargo, en las cuestiones de familia es muy diferente. Pongamos el ejemplo de una madre que se niega a dar cumplimiento con el régimen de visitas establecido a favor del padre de sus hijos, no existe indemnización que compense de manera alguna el daño provocado a ese progenitor y a los niños por el incumplidor, debiendo la justicia, mediante todos los medios que se encuentren a su alcance, lograr el cumplimiento "en especie” de la obligación.

Tomando en consideración que el Juzgado no puede intervenir por medio de la fuerza pública cada vez que le corresponda al padre ver a sus hijos, la mejor opción resulta persuadir al incumplidor a que se avenga al cumplimento de la manda judicial por su propia voluntad.

Nuestro derecho da una solución en este sentido, y la misma consiste en la aplicación de astreintes al incumplidor.

\section{LAS ASTREINTES COMO MEDIO DE CONSTRICCIÓN AL CUMPLIMIENTO}

El art. 804 del Código Civil y Comercial de la Nación establece que:

Los jueces pueden imponer en beneficio del titular del derecho, condenaciones conminatorias de carácter pecuniario a quienes no cumplen deberes jurídicos impuestos en una resolución judicial. Las condenas se deben graduar en proporción al caudal 
económico de quien debe satisfacerlas y pueden ser dejadas sin efecto o reajustadas si aquél desiste de su resistencia y justifica total o parcialmente su proceder. La observancia de los mandatos judiciales impartidos a las autoridades públicas se rige por las normas propias del derecho administrativo.

El Código Civil y Comercial habla de "condenaciones conminatorias" para referirse a las comúnmente llamadas astreintes, instituto que reconoce su origen en la jurisprudencia francesa y que fue incorporado a nuestro derecho con la reforma introducida al Código Civil por la ley 17.711.

Borda (1976) define a las astreintes como "una condena pecuniaria fijada en razón de tanto por día (o por periodo de tiempo) de retardo en el cumplimiento de la sentencia" (p. 47).

Es un medio de presión psicológica que la ley otorga a los jueces a los fines de constreñir al cese de la reticencia al cumplimiento de una orden por ellos impartida.

De oficio o a pedido de parte, el juez fija una suma de dinero por día, semana, mes, etc. que transcurra sin que la orden dispuesta sea cumplida, razón por la cual Llambías (1979) afirma que "la sanción conminatoria que implican las astreintes afecta al deudor mientras no cumpla lo debido y que por ello es susceptible de aumentar indefinidamente" (p. 455).

Sin embargo, no son definitivas, es decir que el juez puede prolongar su duración (en caso de que esté fijada), aumentarlas, disminuir el monto de las mismas, o dejarlas sin efecto.

Por esta razón se las caracteriza como discrecionales y arbitrarias, siendo que el juzgador puede fijar su monto libremente, sin que el mismo deba guardar relación con la prestación requerida. 


\section{Cumplimiento de las Resoluciones Judiciales en los Procesos Judiciales DE DERECHO DE FAMILIA}

Sin embargo, la norma dispone que el monto de las mismas se gradúe en proporción al caudal económico de quien deba satisfacerlas.

Pueden imponerse ante el incumplimiento de cualquier resolución judicial, no solamente ante la inobservancia de una sentencia definitiva.

Para Moisset de Espanés (s.f.):

Es una característica propia de las sanciones conminatorias que su empleo resulte procedente en todos los casos en que un litigante desobedece mandatos emanados de una "resolución" judicial, no solamente de una "sentencia" en sentido estricto. La doctrina se ha preocupado siempre en destacarlo, y el legislador, tanto en el ámbito procesal, como en el Código Civil han sido cuidadosos en el lenguaje empleado, para evitar que pueda pensarse que las astreintes sólo proceden frente al incumplimiento de sentencias. (p. 1).

La astreintes funcionan como un medio de presión para con el incumplidor, que funciona dentro de la lógica de que si éste no cumple por convicción o apego a las decisiones judiciales, cumplirá para no verse afectado en su economía. En ese sentido es un medio muy efectivo.

\section{IMPOSICIÓN}

El art. 37 del Código Procesal Civil y Comercial de la Nación, al igual que el de la Provincia de Corrientes, dispone que:

Los jueces y tribunales podrán imponer sanciones pecuniarias compulsivas y progresivas tendientes a que las partes cumplan sus mandatos, cuyo importe será a favor del litigante perjudicado por el incumplimiento. Podrán aplicarse sanciones conminatorias a terceros, en los casos en que la ley lo establece. Las condenas se graduarán en proporción al caudal económico de quien deba satisfacerlas y podrán ser 
dejadas sin efecto, o ser objeto de reajuste, si aquél desiste de su resistencia y justifica total o parcialmente su proceder.

La astreintes pueden ser fijadas de oficio o a pedido de parte, pero la mayoría de los casos, es por esta última razón.

El momento procesal para solicitarlas es cuando, ante la intimación judicial al cumplimiento de determinada acción, el requerido hace caso omiso a ésta.

Un ejemplo práctico: en un juicio de divorcio, la esposa solicita medidas cautelares sobre los bienes de la comunidad conyugal que se encuentran bajo el poder y administración del otro cónyuge. El juzgado, en este sentido ordena el depósito del 50\% de las sumas de dinero que éste recibe en concepto de alquiler de un conjunto de departamentos comunitarios. El marido es notificado de la resolución, deja consentir la misma y no deposita las sumas ordenadas. En virtud de dicho incumplimiento la esposa solicita se realice una nueva intimación, esta vez bajo expreso apercibimiento de aplicación de astreintes.

Somos de la opinión de que ante esta solicitud de parte, el Juzgado debe fijar el monto de las astreintes bajo cuyo apercibimiento se intimará al incumplidor. Sin embargo, es práctica de los Juzgados de familia del foro de Corrientes hacer primero una intimación genérica, sin explicitar el monto de la sanción, la que posteriormente será fijada ente la reiteración del incumplimiento y ante nueva solicitud de parte. Esto, en la práctica, significa otorgarle más tiempo al moroso de mantenerse en una situación irregular sin recibir sanción alguna y la extensión en el tiempo del daño que le genera al damnificado el incumplimiento.

Continuando, una vez que el juez fija el monto de las astreintes y el tiempo para el cumplimiento de la manda judicial, se vuelve a intimar a la parte, por cédula. Un ejemplo de providencia de fijación de astreintes sería: “(...) atento al incumplimiento 


\section{Cumplimiento de las Resoluciones Judiciales en los Procesos Judiciales DE DERECHO DE FAMILIA}

de la intimación efectuada, hacer saber al Sr. X. que deberá cumplir con lo ordenado dentro de las 48 hs. de notificado de la presente, caso contario se hará pasible de lo dispuesto por el art. 239 del Código Penal y un astreinte diario de PESOS CIEN $(\$ 100,00)$ que correrán desde que se opere el vencimiento de la presente intimación hasta su efectivo cumplimiento (art.804 del Código Civil y Comercial de la Nación)..."

$\mathrm{Si}$ ante este requerimiento, la parte no cesa su reticencia, el damnificado queda habilitado para solicitar la ejecución de las astreintes.

\section{EJECUCIÓN}

Las resolución que fija las astreintes es ejecutable mediante el procedimiento de la ejecución de sentencia, siéndole aplicables las normas relativas a estos procedimientos.

Es que, como dicen Cazeaux \& Trigo Represas (1975), si no pudieran ser ejecutadas, perderían toda su fuerza y eficacia. Agregan, sin embargo, que no son ejecutables ni bien son impuestas, ya que hay que aguardar la conducta que asumirá el obligado, es decir, si finalmente cumple, o si justifica su proceder.

Pero si nada hace y continúa con su comportamiento reticente, el juez, a pedido de parte, deberá disponer la ejecución de las astreintes.

¿Cuándo queda habilitada entonces la vía para ejecutar estas sanciones? Este punto lo explicaremos con un caso práctico, que se dio en la realidad en los tribunales de familia de la ciudad de Corrientes.

En un incidente de medidas cautelares iniciado en un juicio de divorcio, la incidentista (actora) solicitó se intime al demandado (quien tenía la administración de hecho de todos los inmuebles de la sociedad conyugal) para que en el perentorio 
término de 24 horas de notificado, deposite en esos autos el porcentaje de todos y cada uno de los alquileres que recibía por uno de esos inmuebles, bajo apercibimiento de aplicar astreintes por cada día de retraso, a fijarse por el juzgado.

Dicha petición fue proveída en estos términos: "intímese como se pide".

La intimación se efectivizó mediante el libramiento de la correspondiente cédula, no cumpliendo el demandado con la orden en el plazo dispuesto.

Consecuentemente, la actora solicitó se haga efectivo el apercibimiento y se apliquen astreintes por cada día de retraso, siendo que, el demandado, estando debidamente notificado, no dio cumplimiento a la manda judicial.

En virtud de la petición de parte, el Juzgado resolvió intimar al accionado a cumplir con lo ordenado dentro de las 48 horas de notificado, so pena de ser pasible de lo dispuesto por el art. 239 del Código Penal y un astreinte diario de pesos cien que correrían desde que se opere el vencimiento de la intimación hasta su efectivo cumplimiento conforme lo dispuesto por el, en ese momento vigente, art. 666 bis del Código Civil.

Dicha providencia le fue notificada por cédula al demandado, quien no solo no cumplió la manda judicial, sino que tampoco recurrió la medida dispuesta, consintiéndola.

En virtud de ello y ante la prolongación en el tiempo de la inobservancia de la manda judicial, la actora promovió el correspondiente incidente de ejecución de sentencia, solicitando al juzgado la ejecución de las astreintes devengadas hasta el momento, resolviendo éste último en forma negativa a dicha petición. Fundó su decisión en el hecho de que de las constancias incidente de medida cautelar, donde éstas habían sido fijadas, no surgía a esa fecha, que se haya efectivizado el apercibimiento contenido 


\section{Cumplimiento de las Resoluciones Judiciales en los Procesos Judiciales DE DERECHO DE FAMILIA}

en el auto que fijaba la suma de $\$ 100$ diarios como astreintes, señalando que la exigibilidad de las mismas se encuentra supeditada al carácter firme de la resolución que las haya impuesto.

En otras palabras, el juez negó la existencia de un título que habilite la ejecución de las astreintes fijadas, pretendiendo el dictado de un nuevo decreto que estableciera la firmeza y ejecutabilidad de las mismas.

La actora apeló esta decisión, en el entendimiento de que la exigibilidad de las astreintes se encuentra únicamente supeditada al carácter firme del decreto que las impuso, habiendo el requerido incurrido en mora de pleno derecho a las 48 horas de haber sido notificado de la resolución que fijaba el monto de las astreintes, de cuya aplicación ya había sido previamente intimado, sin haber cumplido.

La Cámara de Apelaciones en lo Civil y Comercial de la ciudad de Corrientes, Sala III, acogió la pretensión de la ejecutante en el entendimiento de que:

La ejecutoriedad y firmeza del auto que las impuso es verificable, atendiendo a la naturaleza y los caracteres propios de las astreintes, en cuanto estas son discrecionales, conminatorias y alcanzan a quienes después de haber sido dictadas, persisten en su incumplimiento, la firmeza de la Resolución en virtud que debidamente notificada (ver constancias de fs. 7 y vta.), la parte no la impugnó en tiempo propio, ni en tiempo alguno, de acuerdo surge de las constancias propias del Expte. I10-32372/1 que se tiene a la vista. En el caso, por decreto $\mathrm{N}^{\circ} 10799$ se dispuso “... A lo demás, no habiéndose acreditado la imposibilidad que se menciona, y atento al cumplimiento de la intimación efectuada, hacer saber al Sr. C. que deberá cumplir con lo ordenado dentro de las 48 hs. de notificada la presente, caso contrario será pasible de lo dispuesto por el art. 239 del Código Penal y un astreinte diario de PESOS CIEN (\$100) que correrán desde que se opere el vencimiento de la presente intimación hasta su efectivo cumplimiento (art.666 
bis del Código Civil)." El subrayado pertenece a la suscrita, y se afecta en el entendimiento que a partir del vencimiento de la notificación del auto aludido, las astreintes hubieron adquirido la eficacia necesaria para su ejecución. La mentada resolución contiene todos los requisitos necesarios y exigibles para proceder a su ejecución, a saber, monto de las mismas y momento a partir del cual comenzarán a aplicarse. En lo que refiere al destino de los fondos, el decreto que las impone claramente establece que se originan en lo dispuesto por el art. 666 bis del Código Civil. Así, va de suyo que fueron decretadas en beneficio al acreedor y como medio compulsivo para cumplir un mandato judicial. (...) Lo esencial y que hace entiende al aspecto formal del título, es que debe haber pronunciamiento expreso, este aspecto hubo quedado cubierto con el dictado del interlocutorio $\mathrm{N}^{\circ} 10799$, el que ha sido claro, concreto y preciso. Este interlocutorio ya indica que medió un incumplimiento anterior, una intimación ya efectuada e incumplida, por lo cual de no cumplir esta será pasible de un astreinte diario que la misma resolución impone y establecido el monto y el momento a partir del cual se harán efectivas. Vencido el plazo contenido en el resolutorio, lo cual aconteció y fue notificado al deudor, corren como la misma resolución lo indica desde que opere el vencimiento de dicha intimación.

\section{CONCLUSIÓN}

Las astreintes son un medio efectivo para conminar al cumplimiento de una orden judicial a la parte que es reticente a ello, especialmente en el derecho de familia, donde, la mayoría de las veces, las acciones cuya ejecución se pretende por vía judicial no son sustituibles por dinero.

Este medio de presión representa muchas veces la única forma de lograr, por ejemplo, el cumplimiento de un régimen de visitas, la presentación de documentación de la sociedad conyugal, y tantas otras situaciones tan sensibles para los justiciables, 


\section{Cumplimiento de las Resoluciones Judiciales en los Procesos Judiciales DE DERECHO DE FAMILIA}

quienes ante la pregunta ¿y qué pasa si no cumple?, no pueden conformarse con un "nada" como respuesta.

Asimismo, constituyen una herramienta útil en función de facilitar el trabajo de los jueces y formar en los ciudadanos el respeto por las órdenes judiciales. En este sentido, la experiencia judicial indica que no basta con intimar de manera abstracta al cumplimiento de una orden, o aplicar sanciones que jamás serán ejecutadas, ya que esa falta de rigidez es la que termina alimentando y contribuyendo al desacato.

Además, otra ventaja de las astreintes, es que, si bien son un medio muy eficaz de constricción al cumplimiento de las órdenes judiciales, no constituyen una sanción que genere un daño irreparable contra el incumplidor que eventualmente pueda justificar su accionar, ya que, al ser provisorias, graduables e incluso pasibles de ser dejadas sin efecto, el juez, sin ningún problema, y atendiendo a las características del caso, puede revisar su decisión.

Es este otro motivo más para que los tribunales no teman aplicarlas.

\section{REFERENCIAS BIBLIOGRÁFICAS}

Borda, G. A. (1976) Tratado de Derecho Civil: Obligaciones. I. (4ta. ed.) Buenos Aires: Abeledo Perrot.

Compagnucci de Caso, R. H. (2014) Obligaciones con cláusula penal y sanciones conminatorias. En Rivera, J. C. y Medina, G. (Ed.) Código Civil y Comercial de la Nación comentado, Tomo III, artículos 724 a 1250 (pp. 116). Buenos Aires: Thomson Reuters La Ley.

Cazeaux P.N. \& Trigo Represas, F.A. (1975) Derecho de las Obligaciones (2da. ed.) La Plata: Librería Editora Platense. 
Código Civil de la Nación. B.O. (26 de abril de 1968).

Código Civil y Comercial de la Nación. B.O. (08 de octubre de 2014).

Código Procesal Civil y Comercial de la Nación B.O. (07 de noviembre de 1967).

Llambías, J. J. (1979), Código Civil Anotado, Tomo II A. Buenos Aires: Abeledo Perrot.

Moisset de Espanés L. (s.f.) Las "astreintes" y la desobediencia de resoluciones judiciales. Recuperado el 12 de octubre del 2014 de: http://www.acader.unc.edu.ar

Cámara de Apelaciones en lo Civil y Comercial de la ciudad de Corrientes. Sala III, Sent. $N^{\circ} 189,27 / 08 / 2014$.

\section{Currículum Vítae}

Especialista en Derecho Agrario.

Correo electrónico: manuela_schulz@hotmail.com 